\title{
Analysis on the Allocation Efficiency of Traditional Chinese Medicine Resource in Tianjin Based on DEA Model
}

\author{
Yanhui $\mathrm{Nie}^{1}$ and Ning $\mathrm{He}^{1, *}$ \\ ${ }^{1}$ School of Management, Tianjin University of Traditional Chinese Medicine, Tianjin, 301617, China \\ *Corresponding author. Email: hening837@126.com
}

\begin{abstract}
This paper aims to understand the allocation efficiency of health resource about Traditional Chinese Medicine (TCM) in Tianjin from 2011 to 2019, and to provide suggestions for the allocation of TCM resource during the 14th five-year Plan period. Descriptive analysis was conducted on the allocation of TCM resource in Tianjin from 2011 to 2019, and Data Envelopment Analysis (DEA) was used to study the allocation efficiency and input-output projection of TCM resource in Tianjin. From 2011 to 2019, the allocation and service output of TCM resource in Tianjin increased in some degree. DEA results showed that the allocation of TCM resource was generally effective, and TCM institutions had excess input and insufficient output of health resource in 2015, 2017 and 2018. Considering the output and input of TCM resources in Tianjin from 2011 to 2019 is mismatch, and the structure of resource allocation and investment is poor. Combined with the scale efficiency of resource allocation is low, and resource input redundancy and output deficiency coexist at the same time. It is suggested that control the scale expansion of health resource in TCM institution rationally; enhance the service level of TCM institution; establish scientific assessment and evaluation standard. Keywords: Tianjin; Traditional Chinese Medicine; Health resource; DEA model; Efficiency evaluation
\end{abstract}

\section{INTRODUCTION}

TCM is an important health resource, excellent cultural resource, economic resource with potential, and scientific and technological resource with original advantages. In recent years, the state has issued a series of policies to develop the TCM industry. Tianjin is a developed city in the North China which not only has profound culture of TCM, but also reaches outstanding achievements and stays good momentum in the development of TCM health cause. Meanwhile, there are still some deep-seated problems that need to be further studied and solved. Existing studies don't focus on TCM resource, and lack of prospective recommendation about health policy. This study combines qualitative and quantitative methods based on two dimensions of input and output, problems in the development of TCM health service in Tianjin were found and the corresponding countermeasures were put forward by evaluating the allocation efficiency of TCM resource, so as to provide suggestions for the development of TCM health service in Tianjin during the 14th five-year Plan period. The advantages of this study are that the data is comprehensive and the analysis is targeted.

\section{DATA AND METHODOLOGY}

\subsection{Data Source}

The input data on health resource and output data on health service related to TCM institution in Tianjin are collected through Health Statistics of Tianjin from 2011 to 2019.

\subsection{Research Methodologies}

The trend of TCM resource allocation and service output in Tianjin from 2011 to 2019 is studied by using descriptive analysis method; the $\mathrm{BC}^{2}$ model of DEA is used to study the allocation efficiency of TCM resources; the $C^{2} R$ model of DEA is used to calculate the input-output projection.

\subsection{Statistical Tools}

Excel2016 is used for summary and descriptive analysis; DEAP2.1 is applied to efficiency analysis. 


\section{RESULTS AND ANALYSIS}

\subsection{Distribution of TCM resource in Tianjin from 2011 to 2019}

On the whole, the number of TCM institutions, actual bed, health technician and equipment over $10000 \mathrm{CNY}$ in Tianjin has increased significantly from 2011 to 2019, but the difference in growth rate is great. Medical institution and equipment over $10000 \mathrm{CNY}$ increased by more than $100 \%$; the increase of actual bed and health technician was relatively slow, neither exceeding $50 \%$ as shown in Table 1 below.

Table 1. Distribution of TCM health resources in Tianjin from 2011 to 2019

\begin{tabular}{|c|c|c|c|c|}
\hline Year & $\begin{array}{c}\text { Number of the } \\
\text { institution(unit) }\end{array}$ & $\begin{array}{c}\text { Number of actual } \\
\text { bed(sheet) }\end{array}$ & $\begin{array}{c}\text { Number of health } \\
\text { technician(person) }\end{array}$ & $\begin{array}{c}\text { Number of } \\
\text { equipment over 10, } \\
\text { 000 CNY(set) }\end{array}$ \\
\hline 2011 & 78 & 6824 & 9926 & 4789 \\
\hline 2012 & 88 & 6935 & 10174 & 5366 \\
\hline 2013 & 99 & 7385 & 10205 & 5907 \\
\hline 2014 & 112 & 7516 & 10625 & 6992 \\
\hline 2015 & 138 & 8776 & 12734 & 8953 \\
\hline 2016 & 151 & 9050 & 12453 & 6828 \\
\hline 2017 & 157 & 9296 & 12971 & 11187 \\
\hline 2018 & 162 & 9655 & 13669 & 11754 \\
\hline 2019 & 183 & 9783 & 14097 & 13086 \\
\hline Growth rate(\%) & 134.62 & 43.36 & 42.02 & 173.25 \\
\hline $\begin{array}{l}\text { Average annual } \\
\text { growth rate(\%) }\end{array}$ & 16.83 & 5.42 & 5.25 & 21.66 \\
\hline
\end{tabular}

Table 1 shows that there were 78 TCM institutions in 2011 in Tianjin which maintained so strong trend of growth that the number of TCM institution in 2019 was about 2.35 times compared with that in 2011 ; the number of actual bed increased yearly which was 6824 then added up to 9783 with an increase rate of $43.36 \%$;the number of health technician keeps growing which was 9926 has risen up to 14097 and the growth rate is $42.02 \%$; different from the three kinds of resource above which show a continuous increasing, although the number of equipment over 10000 CNY increased from 4789 to 13086 , it's growth rate is as high as $173.25 \%$ which on behalf of the fastest growth trend among them, however, the fluctuation of it in the past nine years were volatile.

\subsection{Variation of TCM health service in Tianjin from 2011 to 2019}

During 2011 to 2019, the capacity of health service about TCM in Tianjin has gradually improved, but the growth rate was not high and lower than that of TCM resource, and relatively large gap exists in rise extent of the four indexes as shown in Table 2.

Table 2. Quantity of TCM health service in Tianjin from 2011 to 2019 (unit: person)

\begin{tabular}{|c|c|c|c|c|}
\hline Year & $\begin{array}{c}\text { Number of } \\
\text { outpatient and } \\
\text { emergency patient }\end{array}$ & $\begin{array}{c}\text { Number of total } \\
\text { patients }\end{array}$ & $\begin{array}{c}\text { Number of inpatient } \\
\text { undergoing surgery }\end{array}$ & $\begin{array}{c}\text { Number of } \\
\text { discharged patient }\end{array}$ \\
\hline 2011 & 11091484 & 11379172 & 32065 & 144069 \\
\hline 2012 & 12160620 & 12519816 & 33179 & 154019 \\
\hline 2013 & 13352501 & 13697218 & 35098 & 169709 \\
\hline 2014 & 14485333 & 14903751 & 39683 & 181198 \\
\hline 2015 & 14630071 & 15024496 & 37056 & 203158 \\
\hline 2016 & 14561711 & 14943853 & 44951 & 217161 \\
\hline 2017 & 13702677 & 14142086 & 46168 & 224335 \\
\hline 2018 & 13426871 & 13847914 & 53463 & 234037 \\
\hline 2019 & 13894393 & 14080789 & 62964 & 62.45 \\
\hline Growth rate(\%) & 25.27 & 23.74 & 96.36 & 7.81 \\
\hline $\begin{array}{l}\text { Average annual } \\
\text { growth rate(\%) }\end{array}$ & 3.16 & 2.97 & 12.05 & \\
\hline
\end{tabular}

As shown in Table 2, the changing trend of the number of outpatient and emergency patient and the number of total patients is almost identical, both of them rose slowly in singulos annos before the year of 2015 and decreased 
slightly after the year of 2015, the trend began to rise again until the year of 2019. The number of outpatient and emergency patient increased by $25.27 \%$ and the number of total patients increased by $23.74 \%$ of which the growth is reversely slow compared with the input of TCM resource. While the number of discharged patient and inpatient undergoing surgery increased rapidly.

\subsection{Analysis on the development efficiency of TCM resource allocation in Tianjin from 2011 to 2019}

Taking the number of TCM institution, actual bed, health technician, equipment over 10, $000 \mathrm{CNY}$ as the input indexes, the number of outpatient and emergency patient, total patients, inpatient undergoing surgery, discharged patient were selected as output indicators, $\mathrm{BC}^{2}$ model in DEA was used to analyze the allocation efficiency of TCM resource in Tianjin from 2011 to 2019, the score of allocative efficiency is shown in Table 3.

Table 3. The score of comprehensive efficiency, simple technical efficiency and scale efficiency

\begin{tabular}{|c|c|c|c|c|c|}
\hline Year & $\begin{array}{c}\text { Comprehensive } \\
\text { efficiency }\end{array}$ & $\begin{array}{c}\text { Simple technical } \\
\text { efficiency }\end{array}$ & Scale efficiency & Scale reward & $\begin{array}{c}\text { Relative } \\
\text { validity }\end{array}$ \\
\hline 2011 & 1.000 & 1.000 & 1.000 & - & effective \\
\hline 2012 & 1.000 & 1.000 & 1.000 & - & effective \\
\hline 2013 & 1.000 & 1.000 & 1.000 & - & effective \\
\hline 2014 & 1.000 & 1.000 & 1.000 & - & effective \\
\hline 2015 & 0.878 & 1.000 & 0.878 & drs & mildly invalid \\
\hline 2016 & 1.000 & 1.000 & 1.000 & - & effective \\
\hline 2017 & 0.982 & 1.000 & 0.982 & drs & mildly invalid \\
\hline 2018 & 0.972 & 1.000 & 0.972 & drs & mildly invalid \\
\hline 2019 & 1.000 & 1.000 & 1.000 & & - \\
\hline Mean value & 0.981 & 1.000 & 0.981 & & effective \\
\hline
\end{tabular}

Note: "-" means the scale reward is constant; "ins" means the scale reward is increasing; "drs" means scale reward is diminishing.

Table 3 shows that TCM institutions in Tianjin have achieved effectively developed for 6 years and the comprehensive efficiency value is 1 , meaning the input and output efficiency reached the optimal level; TCM institutions in Tianjin showed mild ineffective development in 2015, 2017 and 2018, the comprehensive efficiency value is greater than 0.8 and close to 1 which indicates that the existing resource input has been fully utilized but the input scale hasn't reached the ideal state. In terms of resource utilization, the annual growth rate of input and output of TCM institutions in Tianjin is $98.1 \%$, the investment and employment efficiency of input indexes are closed to the highest level under the current investment situation. From the development trend of efficiency, the comprehensive and scale efficiency showed an obvious trend of decline, but the overall efficiency remains on the level of 0.8 which indicates a high level of sustainable development in spite of the level of resource input and output fluctuates. Scale reward remains unchanged and shows a decreasing state around 2016, the growth rate of resource input is higher than that of output, indicating that resource input is idle or underutilized.

\subsection{Analysis of input redundancy and output deficiency in DEA non-effective years}

DEA analysis results show that TCM institutions in Tianjin had different degree of overinvestment in health resource in 2015, 2017 and 2018, the scale of investment in TCM institution, actual bed and health technician has been effectively controlled, but investment in equipment over $10000 \mathrm{CNY}$ is still a large number of surpluses. The $\mathrm{C}^{2} \mathrm{R}$ model in DEA is used to calculate the input-output projection, the ideal value and redundancy value of DEA in mildly invalid years are shown in Table 4 .

Table 4. Input redundancy in DEA of mildly invalid years

\begin{tabular}{|c|c|c|c|c|c|c|c|c|}
\hline \multirow{3}{*}{ Year } & \multicolumn{2}{|c|}{$\begin{array}{c}\text { Number of outpatient and } \\
\text { emergency patient }\end{array}$} & \multicolumn{2}{|c|}{ Number of total patients } & \multicolumn{2}{|c|}{$\begin{array}{c}\text { Number of inpatient } \\
\text { undergoing surgery }\end{array}$} & $\begin{array}{c}\text { Number of discharged } \\
\text { patient }\end{array}$ \\
\cline { 2 - 9 } & ideal value & $\begin{array}{c}\text { Slack } \\
\text { variable }\end{array}$ & ideal value & $\begin{array}{c}\text { Slack } \\
\text { variable }\end{array}$ & $\begin{array}{c}\text { ideal } \\
\text { value }\end{array}$ & $\begin{array}{c}\text { Slack } \\
\text { variable }\end{array}$ & $\begin{array}{c}\text { ideal } \\
\text { value }\end{array}$ & $\begin{array}{c}\text { Slack } \\
\text { variable }\end{array}$ \\
\hline 2015 & 14857223.248 & 227152.248 & 15286383.533 & 261887.533 & 40701.804 & 3645.804 & 185850.000 & 0.000 \\
\hline 2017 & 17360287.639 & 3657610.639 & 17861750.521 & 3719664.521 & 47559.024 & 1391.024 & 217161.000 & 0.000 \\
\hline 2018 & 16152042.377 & 2725171.377 & 16539063.010 & 2691149.010 & 53463.000 & 0.000 & 224335.000 & 0.000 \\
\hline
\end{tabular}

It can be seen from Table 4 that there is input redundancy under the condition of constant output. On condition that the ideal value is reached, 23 TCM institutions, 1067 actual beds, 1836 health technicians and 1781 equipments over 
$10000 \mathrm{CNY}$ should be reduced in 2015; 23 TCM institutions, 288 actual beds, 237 health technicians and 2807 equipments over $10000 \mathrm{CNY}$ should be reduced in 2017; 9 TCM institutions, 322 actual beds, 376 health technicians and 1597 equipments over $10000 \mathrm{CNY}$ should be reduced in 2018 .

Relaxation condition of the number of outpatient and emergency patient is synchronized with the number of total patients, the number of operation performed on inpatients has been significantly improved, and the number of discharged patient has always been optimal. Output deficiency in DEA of mildly ineffective years is shown in Table 5 .

Table 5. Output deficiency in DEA of mildly ineffective years (unit: person)

\begin{tabular}{|c|c|c|c|c|c|c|c|c|}
\hline \multirow{2}{*}{ Year } & \multicolumn{2}{|c|}{$\begin{array}{c}\text { Number of } \\
\text { institution(unit) }\end{array}$} & \multicolumn{2}{c|}{$\begin{array}{c}\text { Number of actual } \\
\text { bed(sheet) }\end{array}$} & \multicolumn{2}{c|}{$\begin{array}{c}\text { Number of health } \\
\text { technician(person) }\end{array}$} & \multicolumn{2}{c|}{$\begin{array}{c}\text { Number of equipment } \\
\text { over 10, 000 CNY(set) }\end{array}$} \\
\cline { 2 - 9 } & $\begin{array}{c}\text { ideal } \\
\text { value }\end{array}$ & $\begin{array}{c}\text { redundancy } \\
\text { value }\end{array}$ & $\begin{array}{c}\text { ideal } \\
\text { value }\end{array}$ & $\begin{array}{c}\text { redundancy } \\
\text { value }\end{array}$ & $\begin{array}{c}\text { ideal } \\
\text { value }\end{array}$ & $\begin{array}{c}\text { redundancy } \\
\text { value }\end{array}$ & $\begin{array}{c}\text { ideal } \\
\text { value }\end{array}$ & $\begin{array}{c}\text { redundancy } \\
\text { value }\end{array}$ \\
\hline 2015 & 114.975 & -23.125 & 7708.963 & -1067.037 & 10897.782 & -1836.218 & 7171.510 & -1781.490 \\
\hline 2017 & 134.229 & -22.771 & 9007.727 & -288.273 & 12733.781 & -237.219 & 8379.727 & -2807.273 \\
\hline 2018 & 152.851 & -9.149 & 9333.152 & -321.848 & 13292.713 & -376.287 & 10157.099 & -1596.901 \\
\hline
\end{tabular}

There is a shortage of output when the input is constant. On condition that the ideal value is reached, 227152 outpatients and emergency visits, 261888 total medical visits and 10364 inpatient surgeries should be added in 2015;3657611 outpatients and emergency visits, 3719665 total medical visits and 1391 inpatient surgeries should be added in 2017; 2725171 outpatients and emergency visits, 2725171 total medical visits should be added in 2018 .

\section{DISCUSSION AND SUGGESTIONS}

\subsection{Mismatch between resource output and input}

From 2011 to 2019, the average annual growth rate of the four types of TCM resource in Tianjin is $12.29 \%$, while the average annual growth rate of the four types of TCM health service in the same period is only $6.50 \%$. Overall, TCM health resources have not been fully utilized [1]. It's necessary to be alert to the risk of unreasonable investment in the allocation of TCM resource in recent years, and scientifically allocate TCM resource according to the population flow, structural level, medical demand and geographical situation of Tianjin [2], and rationally control the scale expansion of TCM institution and medical equipment.

\subsection{Structure of resource allocation and input is poor}

The growth of actual bed and health technician is relatively slow with growth rate are below $50 \%$ which directly lead to the internal structure of TCM resource allocation in Tianjin is incomplete, the development of actual bed and health technician cannot be able to keep pace with institution and equipment, it also result in the existing TCM institutions and equipments cannot produce real benefits without the support of actual bed and health

technician[3]. It's supposed to pay attention to the optimization and internal structure adjustment of TCM resource, especially to improve the quantity and quality of manpower resource in the field of TCM, and then strengthen the construction of talent team.

\subsection{Scale efficiency of resource allocation is low}

Study found that allocation efficiency of TCM institution in Tianjin is weakly effective in 2015, 2017 and 2018, with failing to reach the optimal scale efficiency and diminishing return to scale. The direct manifestation is the investment in TCM institution, actual bed, health technician, equipment over $10000 \mathrm{CNY}$ are surplus. The examination standard of TCM service should be improved as soon as possible, and enhance the level of health management through scientific means, like putting forward scientific development planning.

\subsection{Resource input redundancy and output deficiency coexist}

Results show that input indexes were redundant in 2015 , 2017 and 2018, output indicators were insufficient in 2015, 2017 and 2018.So the development of Tianjin TCM case is given priority to input growth, the large scale of investment in TCM has weakened the effective utilization efficiency of resources to a certain extent. To improve the efficiency of the use of health resource, the adjustment of health input is difficult because it involves many aspects of society, while the change of health output is relatively easy[4]. Therefore, TCM institutions in Tianjin can optimize their internal structure by improving management level; building the superior discipline; paying equal attention to traditional Chinese and western medicine; enhancing the core competitiveness; promoting medical service on internet or other ways to boost the quality of medical care and service level [5]. 


\section{CONCLUSION}

In the past nine years, there have been many problems in the allocation of TCM health resources in Tianjin that need structural reform. Since the health system is a whole, many factors should be considered comprehensively when plan the allocation of health resources in the new period [6]. Establish a systematic concept, then improve the service level of TCM institution and enhance the health output, build scientific evaluation criteria to increase the management level of TCM health case. The rational allocation of TCM resource in Tianjin will be realized when the optimization of the structure of TCM resource and the overall improvement of the allocation efficiency promoted.

\section{ACKNOWLEDGMENT}

Fund item: Philosophy and Social Science Research Project in Tianjin (No.TJSSZX20-62)

\section{REFERENCES}

[1] Ebrahim Jafari pooyan, Minoo Alipouri Sakha, Farideh Mohtasham, Hakimeh Mostafavi. The Effect of Resource Allocation Decisions on Efficiency and Equity in the Health Sector: A Systematic Review[J]. Caspian Journal of Health Research, 2018, 3(1).
[2] Li Zhengjun, Yang Lili, Tang Shaoliang, Bian Yaoyao. Equity and Efficiency of Health Resource Allocation of Chinese Medicine in Mainland China: 2013-2017[J]. Frontiers in Public Health, 2020.

[3] Li Qian, Wei Jianjun, Jiang Fengchang, Zhou Guixiang, Jiang Rilei, Chen Meijuan, Zhang Xu, Hu Wanjin. Equity and efficiency of health care resource allocation in Jiangsu Province, China[J]. International journal for equity in health, 2020, 19(1).

[4] Liu Tao, Li Jixia, Chen Juan, Yang Shaolei. Regional Differences and Influencing Factors of Allocation Efficiency of Rural Public Health Resources in China. [J]. Healthcare(Basel, Switzerland), 2020, 8(3).

[5] Jianping Si. Investigation on the Construction of Modern Management System in Traditional Chinese Medicine Hospitals[J]. Chinese Hospital Management, 2019, 39(8):26-28.

[6] Fang Chen, Yuanwei Xiang, Jianhua Jiang, et al. Analysis on efficiency and influence factors of TCM hospital in Guangdong Province[J]. Chinese Health Service Management, 2018, 35(10): 744-747. 